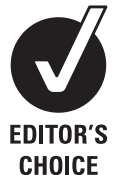

Allergy Department, Cambridge University Hospitals NHS Foundation Trust, Cambridge, UK

\section{Correspondence to}

Dr Shuaib Nasser, Department of Allergy, Cambridge University Hospital, Hills Road, Cambridge CB2 000, UK; Shuaib.nasser@ addenbrookes.nhs.uk

Received 2 December 2011 Accepted 10 March 2012 Published Online First 30 March 2012

\title{
Anaphylaxis: current state of knowledge for the modern physician
}

\author{
Krzysztof Rutkowski, Shelley Dua, Shuaib Nasser
}

\section{ABSTRACT}

Anaphylaxis is a severe, potentially fatal, hypersensitivity reaction of rapid onset. It may trigger life-threatening cardiopulmonary compromise, often with skin and mucosal changes such as urticaria and angioedema. The prevalence of anaphylaxis is increasing and the number of cases of fatal anaphylaxis appears to be rising. Food, insect stings, and drugs are the most common triggers. Novel triggers are increasingly seen and include delayed anaphylaxis to red meat, food-dependent exercise-induced reactions and anaphylaxis to monoclonal antibodies. Anaphylaxis is usually lgE mediated, but other mechanisms also play a role for example direct mast cells activation. Differential diagnosis is discussed including asthma, syncope and shock; excessive endogenous histamine, food related syndromes, and some rare diagnoses. Intramuscular epinephrine is first line treatment. The role of other drugs is reviewed. Timed and serial serum tryptase measurements help to confirm the diagnosis. Longterm management is necessary to minimise the risk of recurrence and includes identification of the trigger(s), management of risk factors, education on avoidance and a formalised treatment plan with an epinephrine auto-injector if appropriate. Every patient who has experienced anaphylaxis should be referred to an allergy clinic for appropriate management. This is endorsed by many national guidelines (eg, UK NICE). Anaphylaxis is often misdiagnosed or miscoded as, for example, asthma or food allergy. Most doctors will encounter a patient with anaphylaxis in their career and should to be familiar with the clinical features, management and mechanisms of this potentially fatal condition.

\section{INTRODUCTION}

Anaphylaxis is an acute systemic allergic reaction which may be life threatening. The incidence of anaphylaxis is increasing. ${ }^{1}$ Most doctors will encounter a medical emergency due to anaphylaxis at some point in their careers. Early recognition of the signs and symptoms along with prompt initiation of acute treatment is crucial. However, once the acute reaction has resolved, clinical management should focus on preventing further similar episodes. We aim to provide doctors with a better understanding of the condition by discussing the aetiology and mechanisms of anaphylaxis. In addition, we review the current recommendations for its acute and long term management, including recently published guidelines. $^{1}$

\section{DEFINITION}

Historically, the definition of anaphylaxis has been an area of contention because it is a condition with a variety of underlying mechanisms presenting with a spectrum of clinical features. However, the current consensus is that anaphylaxis is a severe hypersensitivity reaction of rapid onset that, if left untreated, may cause death. ${ }^{2}$ There is usually a swift progression of skin changes and development of life threatening airway, respiratory or cardiovascular compromise, or any combination of these three features.

\section{EPIDEMIOLOGY}

Prevalence rates reported in the literature vary, and population based estimates are not always reliable due to misdiagnosis, underreporting, and incorrect clinical coding. However, most reports suggest lifetime prevalence rates within the range of $0.5-2 \%{ }^{3}$

The prevalence has been increasing for reasons that are not yet clear. A UK study illustrated a sevenfold increase in the number of hospital admissions for anaphylaxis over a period of 15 years (1990-2005). ${ }^{4}$ In younger age groups the prevalence of food induced anaphylaxis has increased disproportionally. An Australian study detected a fivefold increase in hospital admissions for food mediated anaphylaxis over a 10 year period in children aged 0-4 years. ${ }^{5}$ Additionally, the number of cases of fatal anaphylaxis is believed to be rising. ${ }^{67}$ In the UK 20 deaths per year from anaphylaxis are reported, although this may underestimate the true rate. ${ }^{8}$

\section{CLINICAL FEATURES}

Anaphylaxis presents with a range of clinical symptoms of varying severity, many of which can present in other conditions associated with severe systemic compromise. The diagnosis is therefore made by the typical pattern of clinical features with rapid progression of symptoms, often with a history of a preceding trigger. However, the clinical presentation varies considerably depending on individual hypersensitivity, the dose and route of trigger delivery, as well as individual traits such as the presence of asthma. The diagnosis of anaphylaxis should be made if a patient develops an acute illness (within minutes of exposure to the trigger) with rapidly progressing skin changes, and life threatening airway and/or breathing and/or cardiovascular compromise. Anaphylaxis frequently produces signs and symptoms within 5-30 min after exposure to a trigger, although sometimes symptoms may not develop for several hours (figure 1). 
Cutaneous manifestations are most common, affecting over $90 \%$ of reported cases. ${ }^{9}$ These features include flushing, pruritus, urticaria, and angioedema. Other clinical features of anaphylaxis include bronchospasm, laryngeal oedema, hypotension, and cardiac arrhythmias. Some patients also describe gastrointestinal symptoms of nausea, diarrhoea, and abdominal pain. An overwhelming feeling of 'impending doom' is common. ${ }^{10}$ In severe anaphylaxis rapid cardiovascular compromise and shock can occur without preceding cutaneous features. For example, in intraoperative anaphylaxis, cardiovascular compromise may be the only presenting sign. ${ }^{11}$ Special attention should be paid to infants who may be unable to describe their symptoms. However, some presenting features such as flushing, hoarseness after a crying spell, and vomiting after feeding may be evident in healthy infants, leading to misdiagnosis.

\section{Anaphylaxis and the heart}

Anaphylaxis may be complicated by myocardial ischaemia and arrhythmias even without underlying cardiac pathology and in the absence of epinephrine administration. ${ }^{12}$ Tachycardia is the norm in anaphylaxis. However, when volume depletion exceeds $20-30 \%$, tachycardia may be followed by bradycardia (two phase physiological response to hypovolaemia). Therefore, heart rate does not always differentiate between anaphylaxis and vasovagal reaction. ${ }^{13} 14$ Moreover, bradycardia may occur in response to the drug taken or may be associated with a conduction defect. Vasodilatation during anaphylaxis impairs venous filling, leading to empty vena cava syndrome if the patient suddenly assumes an upright position. Pulseless electrical activity ensues, followed by myocardial ischaemia and subsequently epinephrine-unresponsive shock due to lack of circulatory volume. ${ }^{15}$

\section{Fatal anaphylaxis}

Fatalities are rare and estimated to occur in $<2 \%$ cases. ${ }^{16}$ Predisposing factors for fatal anaphylaxis include coexistent asthma and in particular poorly controlled asthma. ${ }^{17}$ This is especially relevant in the context of food allergy such as peanut and tree nut allergy. ${ }^{18}$ A delay in administration of epinephrine is an important risk factor for death and is seen in $80-87 \%$ of fatal cases. ${ }^{19} 20$

\section{CAUSES OF ANAPHYLAXIS}

There are a wide variety of triggers for anaphylaxis and their frequency varies according to age. In children, food is the most common cause whereas drugs are more common in adults. ${ }^{20} 21$

\section{Food}

Nuts are frequently associated with food mediated anaphylaxis, with peanut being the most common cause in the USA. ${ }^{22}$

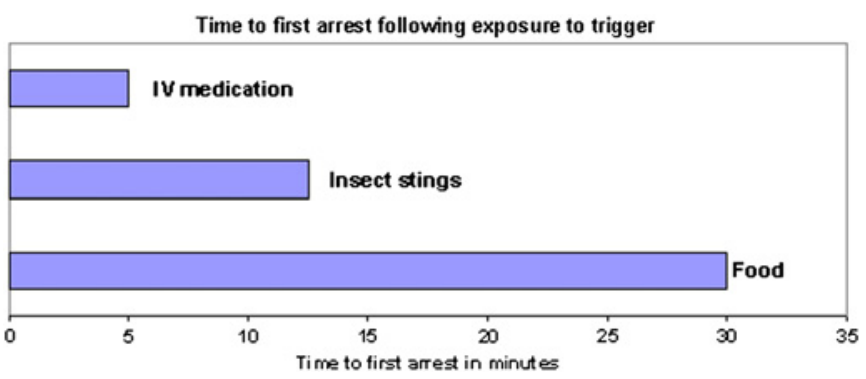

Figure 1 Timing of fatal anaphylaxis in relation to different triggers. IV, intravenous. Adapted from Pumphrey.
Table 1 Mechanism of anaphylaxis ${ }^{9} 1328$ 51-54

\begin{tabular}{ll}
\hline Mechanism & Trigger \\
\hline IgE mediated & Food (eg, nuts, milk, shellfish), insect venom, \\
& $\beta$-lactams, NMBA (eg, suxamethonium), latex, \\
& occupational allergens (wheat flour in bakers), \\
& semen, aeroallergens
\end{tabular}

Non-IgE immune mediated (IgM or IgG mediated cytotoxicity, immune complexes, leukotrienes, activation Radio-contrast media, dextran, gelatin, NSAID, some biologics

of complement, kalikrein-kinin and coagulation cascade)

Direct, non-immune mediated mast Exercise, cold, drugs (vancomycin, opioids) cell activation

IG, immunoglobulin; NMBA, neuromuscular blocking agents; NSAID, non-steroidal antiinflammatory drugs.

These reactions have a tendency to be more severe and can occur with the first recognised exposure. ${ }^{23}$ Moreover, nuts are often hidden in foods and accidental exposure is sometimes difficult to avoid. Geographic variation affects which foods predominate as causes of anaphylaxis. Buckwheat and rice are more common causes in parts of Asia and sesame in parts of the Middle East. ${ }^{24} 25$

\section{Insect stings}

Insects of the order Hymenoptera can cause anaphylaxis, namely bees (honey bees, bumble bees), vespids (yellow jackets, hornets, wasps), and stinging ants. Systemic allergic reactions to insect stings are reported by up to $3 \%$ of adults and up to $1 \%$ of children. ${ }^{26} 27$ The onset of anaphylaxis following insect stings can be rapid.

\section{Drugs}

The most common classes of drugs triggering anaphylaxis include antibiotics, usually $\beta$-lactam antibiotics, and nonsteroidal anti-inflammatory drugs (NSAIDs) ${ }^{28}$ Biological agents increasingly are identified as causes of anaphylaxis, resulting from their growing in use in clinical practice. The estimated rate of anaphylaxis and immunoglobulin $\mathrm{E}(\mathrm{IgE})$ mediated reaction to infliximab, for example, is $2-3 \%{ }^{29}$ For accurate diagnosis of anaphylaxis following drug administration a thorough history is vital, including the exact timing of when the agent was administered, the interval to the reaction, medications that

Table 2 Major mediators of anaphylaxis ${ }^{9} 13 \quad 1844 \quad 50-52 \quad 57$

\begin{tabular}{ll}
\hline Mediators / cells & Action \\
\hline Histamine (via H1-H4 & $\begin{array}{l}\text { Pruritus, tachycardia, rhinorrhoea, bronchospasm (H1) } \\
\text { histaminergic }\end{array}$ \\
Endothelial release of nitric oxide (NO) leading to \\
vasodilatation and hypotension (H1) \\
Hypotension, flushing and headache (H1, 2) \\
Inhibitory presynaptic (H3)-release endogenous \\
epinephrine \\
Chemotaxis and mast cell cytokine release (H4) \\
Activates: complement, coagulation and kalikrein-kinin \\
system leading to angioedema, hypotension, and \\
disseminated intravascular coagulation \\
Respiratory and gastrointestinal tract mast cells \\
contain less tryptase than connective tissue mast \\
cells (tryptase may not increase in food anaphylaxis) \\
Responsible for systemic mast cell activation; \\
high concentration of PAF and low concentrations of \\
PAF-acetylhydrolase may predispose to severe reaction \\
factor (PAF) & Low serum ACE concentrations may also contribute \\
& to severe anaphylaxis \\
& Pro-inflammatory (release mediators from their granules) \\
& Anti-inflammatory (metabolise vasoactive substances) \\
\hline
\end{tabular}


the patient had received previously, and the response to therapy. ${ }^{30}$

\section{Anaphylaxis at the time of anaesthesia}

The reported incidence of anaesthetic induced anaphylaxis varies between 1 in 4000 and 1 in 25000 . The mortality rate has been suggested as $4 \%{ }^{31}{ }^{32}$ Neuromuscular blocking agents are the most common triggers. ${ }^{33}$ The diagnosis of anaphylaxis during anaesthesia poses challenges. Patients are unable to report symptoms and the first signs are often profound hypotension or difficulty in inflating the lungs. Additional diagnostic problems occur due to the concomitant administration of several anaesthetic agents, antibiotics and intravenous fluids such as gelofusine. Other potential agents such as chlorhexidine, patent blue and latex should also be considered.

\section{Exercise induced anaphylaxis}

In some patients exercise alone can trigger anaphylaxis. Many patients, however, require one or more co-factors to be present in order to develop symptoms. Food dependent, exercise induced anaphylactic reactions are becoming more prominent. ${ }^{34}$ Foods most commonly implicated include wheat, shellfish, tomatoes, peanuts, and corn. They are usually ingested $4-6 \mathrm{~h}$ before exercise. ${ }^{35}$ Other reports suggest that the combination of any solid food and exercise may trigger a reaction. ${ }^{36}$ NSAID, alcohol, menstruation or seasonal pollen exposure in pollen sensitised individuals have also been implicated as co-triggers. ${ }^{36-38}$ Typically, exposure to the trigger precedes the exercise which then provokes symptoms of anaphylaxis. Changes in plasma $\mathrm{pH}$ and osmolality redistribution of splanchnic blood flow, increased tissue transglutaminase (tTG) activity, increased gastrointestinal permeability, and facilitated epitope recognition/allergen binding may all be responsible for food dependent, exercise induced anaphylaxis, but they warrant further studies. ${ }^{34} 3637$

\section{Idiopathic anaphylaxis}

Rarely, a trigger cannot be identified and therefore by exclusion a diagnosis of idiopathic anaphylaxis can be considered. However, in the rapidly moving field of allergy with the emergence of new diagnostic tests and increasing knowledge of allergenic mechanisms, triggers can be identified in patients previously considered to have an idiopathic label. A recent example is the delayed anaphylaxis to red meat caused by the galactose- $\alpha$ 1,3-galactose allergenic epitope. ${ }^{12} 3539$ Furthermore, a baseline serum tryptase concentration should be measured in all patients with anaphylaxis to exclude an underlying diagnosis of mastocytosis, which would itself increase the risk of future reactions.
Table 3 Differential diagnosis of anaphylaxis ${ }^{1} 29122528525459$

\begin{tabular}{ll}
\hline Common diagnoses & Acute exacerbation of asthma \\
& Syncope, CVA, epilepsy \\
& Panic attack \\
& Aspiration \\
& CVS pathology (MI, PE) \\
& Shock (hypovolaemic, cardiogenic, septic, etc) \\
& Systemic or indolent mastocytosis \\
Excessive endogenous histamine & Basophilic leukaemia \\
& Scombroid fish poisoning \\
Food related syndromes & Food poisoning \\
('restaurant syndromes') & Menopause related \\
Flushing syndromes & Medullary thyroid carcinoma \\
& Carcinoid syndrome \\
& Pheochromocytoma \\
& Autonomic epilepsy \\
& Red man syndrome (vancomycin) \\
& Other drugs: niacin, bromocriptine \\
& Hyperventilation \\
'Pseudo-anaphylaxis' & Mocal cord dysfunction \\
& Munchausen's (by proxy) syndrome \\
Other & HAE \\
& ACE inhibitor induced angioedema \\
& (ruptured) hydatid cyst
\end{tabular}

CVA, cerebrovascular accident; CVS, cardiovascular system; HAE, hereditary angioedema; $\mathrm{MI}$, myocardial infarction; $\mathrm{PE}$, pulmonary embolism.

\section{DIAGNOSIS AND INVESTIGATION OF ANAPHYLAXIS}

It is sometimes difficult to establish whether anaphylaxis has actually occurred.

The diagnosis relies on the patient's recollection and adequate accident and emergency (A\&E), ambulance or primary care documentation. A meticulous history is essential. Physicians should aim to ascertain a list of all foods and medications consumed in the $6 \mathrm{~h}$ preceding the event. In addition, details regarding the time of the episode, the setting in which it occurred, and the treatment required should be sought. A history of potential cofactors is relevant, including any associated exercise, exposure to heat or cold, or co-existent infections.

\section{Serum tryptase}

It is useful when diagnosing anaphylaxis to look for objective evidence of mast cell activation. Serum tryptase concentrations peak at $1-2 \mathrm{~h}$ after the onset of anaphylaxis, and elevated values can persist for several hours. It is recommended that serum tryptase should be measured as soon as possible after emergency treatment has started, and ideally a second timed sample taken at $1-2 \mathrm{~h}$ and no later than $4 \mathrm{~h}$ after the onset of symptoms. ${ }^{40}$ Serial samples improve the sensitivity and specificity of the test. ${ }^{41}$ In addition, a baseline level should be taken at $24 \mathrm{~h}$, or when the patient attends a specialist clinic for follow-up. Although the positive predictive value is excellent, not all anaphylactic reactions are accompanied by a rise in

Table 4 First line treatment of anaphylaxis ${ }^{12} 286061$

\begin{tabular}{|c|c|c|}
\hline Drug & Recommended dose & Comment \\
\hline Intramuscular epinephrine $(0.01 \mathrm{mg} / \mathrm{kg}$ of $1: 1000)$ & $\begin{array}{l}\text { Adult: } 0.5 \mathrm{ml} \\
>12 \text { years: } 0.5 \mathrm{ml}(0.3 \mathrm{ml} \text { if small or pre-pubertal) } \\
>6-12 \text { years: } 0.3 \mathrm{ml} \\
<6 \text { years: } 0.15 \mathrm{ml}\end{array}$ & Repeat every $5-15$ min \\
\hline Oxygen & Highest possible concentration & $6-8 \mathrm{l} / \mathrm{min}(\mathrm{WAO})$ \\
\hline Intravenous fluids (intra-osseous route possible) & $\begin{array}{l}0.9 \% \mathrm{NaCl} \\
\text { Hartmann's solution }\end{array}$ & $\begin{array}{l}\text { Correct hypovolaemia ( } \mathrm{NaCl} \text { remains in intravascular space } \\
\text { longer than glucose and contains no lactate) } \\
1-2 \text { litres usually needed in first } 5 \text { min (adult); } \\
\text { children } 30 \mathrm{mg} / \mathrm{kg} \text { in the first hour } \\
\text { Anaphylaxis to colloids described }\end{array}$ \\
\hline
\end{tabular}


Table 5 Second line treatment of anaphylaxis ${ }^{12} 1351525660$

\begin{tabular}{lll}
\hline Drug & IV/IM dose & Action \\
\hline $\mathrm{H}_{1}$-antagonists & $\begin{array}{l}\text { Chlorphenamine } 10 \mathrm{mg} \\
\text { (child: } 2.5-5 \mathrm{mg} \text { ) }\end{array}$ & $\begin{array}{l}\text { Control pruritus, urticaria, } \\
\text { angioedema, nasal/ocular } \\
\text { symptoms }\end{array}$ \\
$\mathrm{H}_{2}$-antagonists & $\begin{array}{l}\text { Ranitidine } 50 \mathrm{mg} \\
\text { (child: } 1 \mathrm{mg} / \mathrm{kg} \text { ) } \\
\text { Injected slowly due to } \\
\text { potential hypotensive effect } \\
\text { Hydrocortisone } 200 \mathrm{mg}\end{array}$ & $\begin{array}{l}\text { Small synergistic effect with } \\
\mathrm{H}_{1} \text {-antagonist in limiting } \\
\text { above symptoms }\end{array}$ \\
(child: $25-100 \mathrm{mg}$ ) & $\begin{array}{l}\text { Prevent biphasic anaphylaxis } \\
\text { (delayed onset of action) } \\
\beta \text {-agonists }\end{array}$ & $\begin{array}{l}\text { Salbutamol (albuterol) } \\
\text { Relieve wheeze, cough, dyspnoea }\end{array}$ \\
& $\begin{array}{l}5 \text { mg (child: } 2.5 \mathrm{mg} \text { ) } \\
\text { nebulised }\end{array}$ & \\
\hline
\end{tabular}

serum tryptase, particularly in food mediated anaphylaxis and sometimes in normotensive patients. ${ }^{42}{ }^{43}$ Elevated values of mast cell tryptase postmortem may also be used to establish anaphylaxis as a cause of death. ${ }^{44}$ However, there have been reports of postmortem elevations in serum tryptase in some non-anaphylactic deaths. ${ }^{45} 46$ Therefore, high tryptase concentrations suggest anaphylaxis, but must be used in conjunction with the clinical history supplemented by the circumstances of the death.

Measurement of plasma histamine has been suggested in the literature as a possible investigation in the diagnosis of an anaphylactic reaction. Plasma histamine values begin to rise 5-10 min after the onset of symptoms and remain elevated for 30-60 min. ${ }^{47}$ However, histamine has a short half-life, peaking at $5 \mathrm{~min}$, and is therefore not useful in patients presenting more than an hour after the onset of a reaction. Moreover, plasma histamine is not stable during routine handling and the sample requires careful treatment. Therefore, an assay of plasma histamine is not routinely available.

Elevated total tryptase concentrations are also found in conditions other than mastocytosis and anaphylaxis-for example, in acute myelocytic leukaemia, myelodysplastic syndromes, and end stage renal disease with endogenous stem cell factor elevation. ${ }^{43}$ For this reason other ways of measuring mast cell degranulation are being examined. The measurement of mast cell carboxypeptidase has shown particular promise as an investigative technique. ${ }^{12} 48$ Other markers being studied include chymase and platelet activating factor (PAF). PAF and

Table 6 Special consideration in acute and long term management of anaphylaxis $^{12} 2852546263$

\begin{tabular}{|c|c|}
\hline Group & Special considerations \\
\hline Infants & $\begin{array}{l}\text { Unable to report symptoms } \\
\text { Some symptoms are physiological: flushing, spitting food } \\
\text { after feeding, etc } \\
\text { Correct epinephrine dose should be calculated }\end{array}$ \\
\hline Children & Consider developmental delay/behavioural problems \\
\hline Teenagers & $\begin{array}{l}\text { Risk taking behaviour (non-compliance with prescribed } \\
\text { treatment and avoidance due to denial or peer pressure) }\end{array}$ \\
\hline Elderly & $\begin{array}{l}\text { Consider comorbidities especially involving cardiovascular system } \\
\beta \text {-blockers and ACE inhibitors commonly used } \\
\text { Memory impairment precludes recognition of life threatening } \\
\text { symptoms; physical impairment (severe rheumatoid arthritis, } \\
\text { hearing/vision impairment) hinders epinephrine (auto-injector) } \\
\text { administration }\end{array}$ \\
\hline Pregnancy & $\begin{array}{l}\text { Mother's health is the priority; use epinephrine as in } \\
\text { non-pregnant patient; position on left side to relieve inferior } \\
\text { vena cava compression by gravid uterus; regular fetal monitoring; } \\
\text { consider emergency caesarian section }\end{array}$ \\
\hline All age groups & $\begin{array}{l}\text { Substance/alcohol abuse-interferes with avoidance measures; } \\
\text { impairs recognition of life threatening symptoms and appropriate } \\
\text { self management }\end{array}$ \\
\hline
\end{tabular}

Table 7 Long term management of anaphylaxis ${ }^{1} 1215525459606566$

\begin{tabular}{|c|c|}
\hline Action & Comment \\
\hline Identification of trigger(s) & Box 1 \\
\hline Avoidance and education & $\begin{array}{l}\text { Avoidance of confirmed trigger cornerstone } \\
\text { of long term management } \\
\text { Ensure (child's) relatives and school/nursery } \\
\text { staff educated and trained in using } \\
\text { auto-injectors; verbal, written and online education }\end{array}$ \\
\hline $\begin{array}{l}\text { Epinephrine autoinjector } \\
\text { and treatment plan }\end{array}$ & $\begin{array}{l}\text { Prescribed if ongoing risk of fatal } \\
\text { reactions - for example, insect sting or nut allergy } \\
\text { Train to use } \\
\text { Written treatment plan is essential }\end{array}$ \\
\hline Medic alert bracelet/jewellery & $\begin{array}{l}\text { Document known triggers (penicillins, } \\
\text { NSAID, nuts, insect venom etc) }\end{array}$ \\
\hline Review of regular medication & $\begin{array}{l}\text { Replace/discontinue } \beta \text {-blockers, ACE inhibitors, } \\
\text { sedatives, hypnotics, antidepressants unless no } \\
\text { alternative }\end{array}$ \\
\hline $\begin{array}{l}\text { Management of risk factors } \\
\text { for severe or fatal anaphylaxis }\end{array}$ & $\begin{array}{l}\text { Age related factors, drugs (table } 6 \text { ) } \\
\text { Comorbidities (cardiovascular, asthma, mastocytosis, } \\
\text { other clonal mast cell disorders (c-kit mutation), CNS } \\
\text { impairment) }\end{array}$ \\
\hline Referral to allergy specialist & See box 1 \\
\hline
\end{tabular}

CNS, central nervous system; NSAID, non-steroidal anti-inflammatory drug.

PAF-acetylohydrolase values seem to correlate with the severity of anaphylaxis. ${ }^{49} 50$

\section{PATHOGENESIS OF ANAPHYLAXIS}

The majority of cases of anaphylaxis are IgE mediated, but other mechanisms have been described (table 1) and the clinical presentation can be identical. Therefore the distinction between anaphylactic (IgE mediated) and anaphylactoid (non-IgE) reactions is not possible and should be abandoned as it leads to a dangerous assumption that anaphylactoid reactions are always less severe. $^{12515556}$

In IgE mediated anaphylaxis allergen/antigen-stimulated B lymphocytes produce specific IgE which binds to high affinity IgE receptors (FcERI) on mast cells and basophils. Re-exposure to the allergen leads to cross-linking of receptor bound IgE, triggering cell activation and release of preformed (histamine, tryptase, heparin, chymase) and newly synthesised mediators (leukotrienes, prostaglandins, platelet activating factor PAF, cytokines IL-6, tumour necrosis factor $\alpha(\mathrm{TNF} \alpha)$ ) (table 2). ${ }^{12} 52$

The lungs and the heart are the main shock organs of anaphylaxis, due to vasodilatation caused by reduced venous return and hypovolaemia resulting from fluid extravasation (up to $35 \%$ of the intravascular fluid may leak out within $10 \mathrm{~min}) .{ }^{13} 1458$

\section{DIFFERENTIAL DIAGNOSIS OF ANAPHYLAXIS}

Differential diagnosis of anaphylaxis encompasses a wide range of conditions. Some of them are common (acute asthma, syncope, panic attack) but less common causes should also be considered (table 3).

\section{Useful websites}

UK: http://bsaci.org, http://anaphylaxiscampaign.org;

EU: http://eaaci.net;

US: http://aaaai.com, http://www.acaai.org, http://www.foodallergy.org;

Australia: http://www.allergyfacts.org.au. 
Box 1 Role of allergy specialist in management of anaphylaxis

\section{Role of allergy specialist}

1. Detailed history and elucidation of triggers and co-factors (eg, food dependent, exercise induced anaphylaxis)

2. Skin tests, blood tests including relevant specific $\lg E$

3. Graded challenge and/or provocation if unclear or to identify alternative medication, for example, non-steroidal antiinflammatory drug, antibiotic

4. Individualised avoidance plan

5. Written emergency treatment plan

6. Optimisation of asthma treatment

7. Immunotherapy (eg, for insect venom, etc)

8. Desensitisation to a drug if immediately required and no alternative available

9. Education (verbal, written; online resources)

10. Regular follow-up of patients with 'idiopathic anaphylaxis'

The age and sex of the patient often provides the clue: aspiration of a nut is more likely in a small child; amniotic fluid embolism during labour and a myocardial infarction in a middle aged man. ${ }^{25} 52$

\section{MANAGEMENT OF ANAPHYLAXIS \\ Acute}

1. Discontinue exposure to potential trigger (stop intravenous (IV) drug/remove insect stinger, etc).

2. Follow the ABCDE rule (Airway, Breathing, Circulation, Disability, Exposure).

3. Simultaneously with step 2, administer intramuscular (IM) epinephrine. Lie patient down with legs elevated (to correct hypovolaemia/avoid empty vena cava) or place in a position of comfort (if vomiting or short of breath). While doing this, summon help, administer oxygen, and obtain access to give IV fluids. Start cardiopulmonary resuscitation (CPR) if needed.

Epinephrine is the first line treatment of anaphylaxis and the only one with proven lifesaving properties. Epinephrine vasoconstricts, decreases mediator release and mucosal oedema (via $\alpha 1$-adrenergic receptor); relieves bronchoconstriction ( $\alpha 1$ - and $\beta 2$-adrenergic receptor), and exerts positive inotropic and chronotropic effect ( $\beta 1$-adrenergic receptor). ${ }^{12} 25545660$

There are no randomised controlled trials, but a large body of evidence supports prompt use of epinephrine in anaphylaxis. It should be injected intramuscularly in the mid-anterolateral thigh (vastus lateralis) which leads to a better absorption than

\section{Main messages}

Refer all patients who experience anaphylaxis to an allergy clinic for further investigation and management.

- Explain allergen avoidance, educate the patient and relatives, and provide a written emergency treatment plan including epinephrine auto-injector.

- Serial tryptase measurements are useful in the diagnosis of anaphylaxis.

\section{Current research questions}

How common is anaphylaxis, what are the triggers, and is anaphylaxis on the increase?

- New specific and sensitive markers of anaphylaxisespecially when tryptase is negative.

- What are the likely causes of idiopathic anaphylaxis?

- Newly discovered allergens-what proportion of idiopathic anaphylaxis can they explain?

- What is the role of second line drugs in the acute management of anaphylaxis - for example, do corticosteroids prevent the late phase response?

IM or subcutaneous (SC) injection into the deltoid. Refer to table 4 for dosing. ${ }^{1} 122856$

The length of the needle in crucial in ensuring the dose reaches the muscle. Auto-injectors' needles may be too short in obese patients. In the hospital setting standard syringe and needle are often used allowing for deeper penetration.

Intravenous (1:10000) epinephrine infusion should only be used by intensivists experienced in the use/titration of vasopressors, with continuous haemodynamic monitoring. ${ }^{28} 60$ Intubation and other vasopressors may also be required.

There are no absolute contraindications to epinephrine. Dose adjustment is almost never required in the setting of acute anaphylaxis. ${ }^{60}$ Occasionally described mild transient side effects are the result of physiological action of this drug (pallor, tachycardia, headache, etc). Erroneous intravenous administration or epinephrine overdose may lead to cardiac arrhythmias, pulmonary oedema or even death. ${ }^{12} 2852$

Some drugs interact with epinephrine-for example, $\beta$ blockers (including eye drops) may reduce the efficacy of epinephrine and the unopposed stimulation of $\alpha$ receptors may trigger bradycardia, hypertension, and bronchoconstriction. Glucagon and fluid resuscitation are recommended in the management of anaphylaxis in $\beta$-blocked patients. Linezolid, monoamino oxidase inhibitors (MAOIs), and tricyclic antidepressants increase the risk of arrhythmias and hypertension in response to epinephrine. ${ }^{28} 5960$

\section{Key references}

- Schwartz LB. Diagnostic value of tryptase in anaphylaxis and mastocytosis. Immunol Allergy Clin North Am 2006;26: 451-63.

- Ewan PW, Clark AT. Long-term prospective observational study of patients with peanut and nut allergy after participation in a management plan. Lancet 2001;357:111-15.

- Kemp SF, Lockey RF. Anaphylaxis: a review of causes and mechanisms. J Allergy Clin Immunol 2002;110:341-8.

- Ewan PW, Dugue P, Mirakian R, et al. BSACl guidelines for the investigation of suspected anaphylaxis during general anaesthesia. Clin Exp Allergy 2009;40:15-31.

- Simons FER, Ardusso LRF, Bilo MB, et al. World Allergy Organisation guidelines for the assessment and management of anaphylaxis. J Allergy Clin Immunol 2011;127:593e1-23. 
Other commonly used drugs in the acute management of anaphylaxis should be considered second line, and their administration must never delay treatment with epinephrine (table 5). 4. Measure serum tryptase (see: serum tryptase) and record timing of sample in relation to onset of symptoms.

5 . Patients with uncomplicated anaphylaxis can be discharged after 4-6h. Some should be observed for $24 \mathrm{~h}$ or more (severe reaction; history of severe asthma and biphasic reaction; likely ongoing absorption of allergen; presenting late evening/night; vulnerable patients; patients residing in remote areas) (table 6).

Biphasic anaphylaxis has been reported to occur in up to $20 \%$ adults with symptoms recurring within 1-72 h (usually 8-10 h) after the initial reaction has resolved, despite no further exposure to the trigger. An experienced clinician should be involved in the decision to discharge the patient as there are no definite predictors of biphasic anaphylaxis. Clear instructions to return to hospital if symptoms recur should to be provided, and a 1-3 day course of oral steroids may prevent the delayed recurrence of symptoms. ${ }^{12} 12606364$

6. Long term management (table 7).

7. Role of allergy specialist (box 1).

\section{MULTIPLE CHOICE QUESTIONS (TRUE (T)/FALSE (F); ANSWERS AFTER THE REFERENCES)}
1. What is the most common cause of anaphylaxis in children?
A. Radio-contrast media
B. Stinging insect venom
C. Antibiotics
D. Non-steroidal anti-inflammatory drug (NSAID)
E. Food

\section{Which drug should be avoided in patients with a history of} recurrent anaphylaxis who require an epinephrine auto-injector?
A. Diltiazem
B. Candesartan
C. Propranolol
D. Metoclopramide
E. Domperidone
A. $25-35 \%$
B. $15 \%$
C. $1-20 \%$
D. $40-60 \%$
E. $100 \%$

3. What is the incidence of biphasic anaphylaxis?

\section{The most common agents triggering anaphylaxis at the time of} general anaesthesia are:

A. Neuromuscular blocking agents (NMBA)

B. Opiates

C. Intravenous fluids (Gelofusin, Hartmann's)

D. Iodine preparation

E. Chlorhexidine

\section{Following the onset of anaphylaxis, when do serum tryptase} concentrations peak?
A. $0-10 \mathrm{~min}$
B. $1-2 \mathrm{~h}$
C. $3-4 \mathrm{~h}$
D. $20-30 \mathrm{~min}$
E. $4-5 \mathrm{~h}$

Contributors All authors provided written sections for this review.

\section{Competing interests None.}

Provenance and peer review Commissioned; externally peer reviewed.

\section{REFERENCES}

1. National Institute for Health and Clinical Excellence. NICE Clinical Guideline 134. Anaphylaxis: Assessment to Confirm an Anaphylactic Episode and the Decision to Refer After Emergency Treatment for a Suspected Anaphylactic Episode. 2011:1-95.

2. Sampson HA, Munoz-Furlong A, Campbell RL, et al. Second symposium on the definition and management of anaphylaxis: summary report - Second National Institute of Allergy and Infectious Disease/Food Allergy and Anaphylaxis Network Symposium. J Allergy Clin Immunol 2006;117:391-7.

3. Lieberman $\mathbf{P}$, Camargo CA Jr, Bohlke K, et al. Epidemiology of anaphylaxis: findings of the American College of Allergy, Asthma and Immunology Epidemiology of Anaphylaxis Working Group. Ann Allergy Asthma Immunol 2006;97:596-602.

4. Gupta R, Sheikh A, Strachan DP, et al. Time trends in allergic disorders in the UK Thorax 2007:62:91-6.

5. Poulos LM, Waters AM, Correll PK, et al. Trends in hospitalisations for anaphylaxis angioedema and urticaria in Australia 1993-1994 to 2004-2005. J Allergy Clin Immunol 2007:120:878-84.

6. Shen Y, Li L, Grant J, et al. Anaphylactic deaths in Maryland (US) and Shanghai: a review of forensic autopsy cases from 2004-2006. Forensic Sci Int 2009;186:1-5 (llb)

7. Liew WK, Williamson E, Tang ML. Anaphylaxis fatalities and admissions in Australia. J Allergy Clin Immunol 2009;123:434-42.

8. Pumphrey RS. Lessons for management of anaphylaxis from a study of fatal reactions. Clin Exp Allergy 2000:30:1144-50.

9. Kemp SF, Lockey RF. Anaphylaxis: a review of causes and mechanisms. J Allergy Clin Immunol 2002;110:341-8.

10. Schmidt-Traub S, Bamler KJ. The psychoimmunological association of panic disorder and allergic reaction. Br J Clin Psychol 1997;36:51-62.

11. Dewachter P, Mouton-Faivre C, Emala CW. Anaphylaxis and anaesthesia: controversies and new insights. Anesthesiology 2009:111:1141-50.

12. Simons FE, Ardusso LR, Bilo MB, et al; World Allergy Organization. World Allergy Organisation guidelines for the assessment and management of anaphylaxis. J Allergy Clin Immunol 2011:127:587-93.e1-22.

13. Khan B0, Kemp SF. Pathophysiology of anaphylaxis. Curr Opin Allergy Clin Immunol 2011:11:319-25

14. Fisher MM. Clinical observations on the pathophysiology and treatment of anaphylactic cardiovascular collapse. Anaesth Intensive Care 1988;14;17-21.

15. Pumphrey RS. Fatal posture in anaphylactic shock. J Allergy Clin Immunol 2003:112:451-2

16. Moneret-Vautrin DA, Morisset M, Flabbee J, et al. Epidemiology of life-threatening and lethal anaphylaxis: a review. Allergy 2005:60:443-51.

17. Bock SA, Munoz-Furlong A, Sampson HA. Fatalities due to anaphylactic reactions to foods. J Allergy Clin Immunol 2001;107:191-3.

18. Summers CW, Pumphrey RS, Woods CN, et al. Factors predicting anaphylaxis to peanuts and tree nuts in patients referred to a specialist centre. J Allergy Clin Immunol 2008;121:632-38.e2

19. Pumphrey R. Anaphylaxis: can we tell who is at risk of a fatal reaction? Curr Opin Allergy Clin Immunol 2004;4:205-90.

20. Greenberger PA, Rotskoff BD, Lifschultz B. Fatal anaphylaxis: post mortem findings and associated co-morbid diseases. Ann Allergy Asthma Immunol 2007:98:252-7.

21. de Silva IL, Mehr SS, Tey D, et al. Paediatric anaphylaxis: a 5 year retrospective review. Allergy 2008:63:1071-6.

22. Furlong TJ, DeSimone J, Sicherer SH. Peanut and tree nut allergic reactions in restaurants and other food establishments. J Allergy Clin Immunol 2001;108:867-70.

23. Sicherer SH, Furlong TJ, Munoz-Furlong A, et al. A voluntary registry for peanut and tree nut allergy: characteristics of the first 5149 registrants. J Allergy Clin Immunol 2001;108:128-32.

24. Shek LP, Lee BW. Food allergy in Asia. Curr Opin Allergy Clin Immunol 2006;6:197-201

25. Simons FE. Anaphylaxis: recent advances in assessment and treatment. J Allergy Clin Immunol 2009:124:625-36; quiz 637-8.

26. Golden DB. Insect allergy and venom immunotherapy: a model and mystery. J Allergy Clin Immunol 2005;115:439-47.

27. Golden DB, Marsh DG, Kagey-Sobotka A, et al. Epidemiology of insect venom sensitivity. JAMA 1989;262:240-4

28. Lieberman $\mathbf{P}$, Nicklas RA, Oppenheimer J, et al. The diagnosis and management of anaphylaxis practice parameter: 2010 Update. J Allergy Clin Immunol 2010;126:477-80.e1-42

29. Baert F, Norman M, Vermeire $S$, et al. Influence of immunogenicity on the long term efficacy of infliximab in Crohn's disease. N Engl J Med 2003;348:601-8.

30. Ewan PW, Dugue P, Mirakian R, et al. BSACl guidelines for the investigation of suspected anaphylaxis during general anaesthesia. Clin Exp Allergy 2009; 40:15-31.

31. Hepner DL, Castells MC. Anaphylaxis during the perioperative period. Anaest Analg 2003;97:1381-95.

32. Moss J. Allergic to Anaesthetics. Anaesthesiology 2003;99:521-3. 
33. Mertes $\mathbf{P}$, Laxenaire MC. Allergic reactions occurring during anaesthesia. Eur $\mathbf{J}$ Anaesthesiol 2002;19:240-62.

34. Robson-Ansley P, Du Toit G. Pathophysiology, diagnosis and management of exercise-induced anaphylaxis. Curr Opin Allergy Clin Immunol 2010:10:312-17.

35. Romano A, Di Fonso M, Giuffreda F, et al. Food-dependent exercise-induced anaphylaxis: clinical and laboratory findings in 54 subjects. Int Arch Allergy Immunol 2001;125:264-72

36. Shadick NA, Liang MH, Partridge AJ, et al. The natural history of exercise-induced anaphylaxis: survey results from a 10-year follow-up study. J Allergy Clin Immunol 1999;104:123-7.

37. Harada S, Horikawa T, Ashida M, et al. Aspirin enhances the induction of type I allergic symptoms when combined with food and exercise in patients with fooddependent exercise-induced anaphylaxis. Br J Dermatol 2001;145:336-9.

38. Wade JP, Liang MH, Sheffer AL. Exercise-induced anaphylaxis: epidemiologic observations. Prog Clin Biol Res 1989:297:175-82.

39. Commins SP, Satinover SM, Hosen J, et al. Delayed anaphylaxis, angioedema or urticaria after consumption of red meat in patients with IgE antibodies specific for galactose- $\boldsymbol{\alpha}$-1,3-galactose. J Allergy Clin Immunol 2009;123:426-33.

40. Payne V, Kam P. Mast cell tryptase: a review of its physiology and clinical significance. Anaesthesia 2004;59:695-703.

41. Brown SG, Blackman KE, Heddle RJ. Can serum mast cell tryptase help diagnose anaphylaxis? Emerg Med Australas 2004;16:120-4.

42. Caughey GH. Tryptase genetics and anaphylaxis. J Allergy Clin Immunol 2006;117:1411-14.

43. Schwartz LB. Diagnostic value of tryptase in anaphylaxis and mastocytosis. Immunol Allergy Clin North Am 2006;26:451-63.

44. Yunginger JW, Nelson DR, Squillance DL, et al. Laboratory investigation of deaths due to anaphylaxis. J Forensic Sci 1991:36:857-65.

45. Randall B, Butts J, Halsey JF. Elevated post-mortem tryptase in the absence of anaphylaxis. J Forensic Sci 1995;40:208-11.

46. Edston E, van Hage-Hamsten M. Mast cell tryptase and haemolysis after trauma Forensic Sci Int 2003;131:8-13.

47. Simons FE. Anaphylaxis. J Allergy Clin Immunol 2008;121(2 Suppl):S402-20

48. Schwartz HJ. Anaphylaxis: issues in diagnosis. Curr Opin Allergy Clin Immunol 2001:1:357-9

49. Sanza ML, Gamboab PM, García-Figueroac BE, et al. In vitro diagnosis of anaphylaxis. Chem Immunol Allergy 2010;95:125-40.

50. Vadas $\mathbf{P}$, Gold M, Perelman B, et al. Platelet-activating factor, PAF acetylhydrolase and severe anaphylaxis. N Engl J Med 2008;358:28-35.

51. Lee JK, Vadas P. Anaphylaxis: mechanisms and management. Clin Exp Allergy 2011;41:923-38.

52. Simons FE. Anaphylaxis. J Allergy Clin Immunol 2009;125:S161-81.

53. Lee J, Kim S, Kim M, et al. Anaphylaxis to husband's seminal plasma and treatment by local desensitization. Clin Mol Allergy 2008;6:13-15.
54. Simons FE. Anaphylaxis, killer allergy: long-term management in the community. J Allergy Clin Immunol 2006;117:367-77.

55. Johansson SG, Bieber T, Dahl R, et al. Revised nomenclature for allergy for global use: report of the Nomenclature Review Committee of the World Allergy Organization, October 2003. J Allergy Clin Immunol 2004;113:832-6.

56. Sheikh A, Shehata YA, Brown SG, et al. Adrenaline for the treatment of anaphylaxis: cochrane systematic review. Allergy 2009;64:204-22.

57. Kajiwara N, Sasaki T, Bradding P, et al. Activation of human mast cell through the platelet-activating factor receptor. J Allergy Clin Immunol 2010:125:137-45.

58. Brown SG, Blackman KE, Stenlake V, et al. Insect sting anaphylaxis: prospective evaluation of treatment with intravenous adrenaline and volume resuscitation. Emerg Med J 2004:21:149-54.

59. El-Shanawany T, Williams PE, Jolles S. Clinical immunology review series: an approach to the patients with anaphylaxis. Clin Exp Immunol 2008:153:1-9.

60. Resuscitation Council UK. Resuscitation Guidelines. 2010. http://www.resus.org.uk (accessed 19 Sep 2011).

61. Apostolou E, Deckert K, Puy R, et al. Anaphylaxis to gelofusine confirmed by in vitro basophil activation test: a case series. Anaesthesia 2006;61:264-8.

62. Gonzalez-Perez A, Aponte Z, Fernandez Vidaurre C, et al. Anaphylaxis epidemiology in patients with and patients without asthma: a United Kingdom database review. $J$ Allergy Clin Immunol 2010;125:1098-104

63. Tse Y, Rylance G. Emergency management of anaphylaxis in children and young people: new guidance from the Resuscitation Council (UK). Arch Dis Child Educ Pract Ed 2009;94:97-101.

64. Tole JW, Lieberman P. Biphasic anaphylaxis: review of incidence, clinical predictors, and observation recommendations. Immunol Allergy Clin North Am 2007:27:309-26.

65. Ewan PW, Clark AT. Long-term prospective observational study of patients with peanut and nut allergy after participation in a management plan. Lancet 2001:357:111-15

66. Sicherer SH, Simons FE. Quandaries in prescribing an emergency action plan and self-injectable epinephrine for first-aid management of anaphylaxis in the community. J Allergy Clin Immunol 2005;115:575-83.

\section{ANSWERS}

$A(F) ; B(F) ; C(F) ; D(F) ; E(T)$

2. $A(F) ; B(F) ; C(T) ; D(F) ; E(F)$

3. $A(F)$ : B (F): C (T): D (F): $E(F)$

4. $A(T) ; B(F) ; C(F) ; D(F) ; E(F)$

5. $A(F) ; B(T) ; C(F) ; D(F) ; E(F)$ 